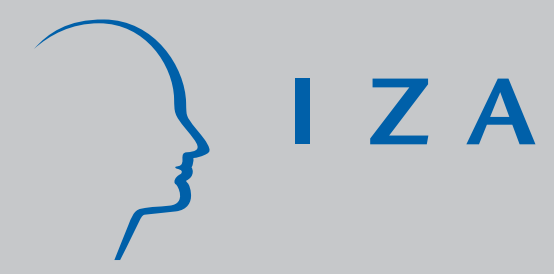

IZA DP No. 888

Collective Dismissal Cost, Product Market Competition and Innovation

Winfried Koeniger

October 2003 


\title{
Collective Dismissal Cost, Product Market Competition and Innovation
}

\author{
Winfried Koeniger
}

IZA Bonn

\author{
Discussion Paper No. 888 \\ October 2003
}

\author{
IZA \\ P.O. Box 7240 \\ D-53072 Bonn \\ Germany \\ Tel.: +49-228-3894-0 \\ Fax: +49-228-3894-210 \\ Email: iza@iza.org
}

This Discussion Paper is issued within the framework of IZA's research area Welfare State and Labor Market. Any opinions expressed here are those of the author(s) and not those of the institute. Research disseminated by IZA may include views on policy, but the institute itself takes no institutional policy positions.

The Institute for the Study of Labor (IZA) in Bonn is a local and virtual international research center and a place of communication between science, politics and business. IZA is an independent, nonprofit limited liability company (Gesellschaft mit beschränkter Haftung) supported by Deutsche Post World Net. The center is associated with the University of Bonn and offers a stimulating research environment through its research networks, research support, and visitors and doctoral programs. IZA engages in (i) original and internationally competitive research in all fields of labor economics, (ii) development of policy concepts, and (iii) dissemination of research results and concepts to the interested public. The current research program deals with (1) mobility and flexibility of labor, (2) internationalization of labor markets, (3) welfare state and labor market, (4) labor markets in transition countries, (5) the future of labor, (6) evaluation of labor market policies and projects and (7) general labor economics.

IZA Discussion Papers often represent preliminary work and are circulated to encourage discussion. Citation of such a paper should account for its provisional character. A revised version may be available on the IZA website (www.iza.org) or directly from the author. 
IZA Discussion Paper No. 888

October 2003

\section{ABSTRACT}

\section{Collective Dismissal Cost, Product Market Competition and Innovation*}

Collective dismissal costs are an important part of employment protection legislation (EPL) and make firms' exit more costly. We show in a model with step-by-step innovations that dismissal costs spur innovation if product markets are not too competitive: technologically more advanced firms endogenously exit with smaller probability so that there is a dynamic incentive to innovate. But dismissal costs decrease the absolute value of firms and induce exit. These opposite effects and their dependence on the policy mix of EPL and product market regulation explain why empirical studies have difficulties to find a negative effect of EPL on innovation.

JEL Classification: J65, L16, O31

Keywords: step-by-step innovations, employment protection legislation, exit cost, Schumpeterian growth

Winfried Koeniger

IZA

P.O. Box 7240

53072 Bonn

Germany

Tel.: +49228 3894512

Fax: +492283894510

Email: koeniger@iza.org

\footnotetext{
*I thank Andrea Bassanini, Giuseppe Bertola, Sebastian Kessing, Stephan Kohns, Omar Licandro and participants of the IZA workshop "European Integration and Labor Market Performance" (especially the discussant Anders Sørensen), the EALE, Paris 2002, and research seminars at the University of Dortmund and the European University Institute for very helpful comments and suggestions.
} 


\section{Introduction}

The effect of market entry and exit on productivity and growth performance has received increasing interest by policy makers in recent years. For example, the Cecchini report (1996) and other more recent ongoing studies for the European commission try to get at the effect of product market reforms in the aftermath of the Single Market Programme. Empirical evidence on the effect of market exit on innovation and growth is scarce and detects no clear relationship between innovation and exit cost across OECD countries (see, e.g., Bassanini and Ernst (2002)). Exit is relatively more expensive in countries with strict employment protection legislation (EPL) since collective dismissal costs are an important component of EPL (see, e.g., OECD (1999)). Cross-country empirical studies and anecdotal evidence by Bassanini and Ernst (2001), Casper and Glimstedt (2001), Estevez-Abe et al. (2001) and OECD (2001) suggest that EPL strengthens incentives for firm-specific and cumulative innovations whereas low turnover costs favor innovations that involve creative destruction.

Theory tells us that in the standard Schumpeterian model of creative destruction, flexibility and low turnover cost in the labor market and a monopoly structure in the product market are always good for growth (see, e.g., Saint-Paul (1996), p. 173). In the model of creative destruction, technology change is characterized by leapfrogging. In models of step-by-step innovations instead (see the seminal paper of Aghion et al. (2001)), product market competition can spur innovations. We show that also the results on turnover cost change: exit cost can spur innovation in a model with step-by-step innovation. The different results are consistent with the suggestive empirical evidence mentioned above since step-by-step innovations have a more cumulative nature: two firms engage in an infinitely repeated duopoly game in which they perform $R \& D$ and then set prices in Bertrand competition. Step-by-step innovations mean that a technology laggard first has to catch up with the technology leader before he can take the lead in the next step. From a technical point of view, the important difference of models with step-by-step innovations is that innovation incentives do not depend on the absolute asset value of the firm as in Schumpeterian models with leapfrogging 
but on the increase of the asset value as firms proceed on the technology frontier. Thus, innovation incentives can increase although the absolute asset value of the firm falls. This is why in contrast to the standard Schumpeterian monopoly model, competition or collective dismissal cost can foster growth although the firms' absolute asset value falls. The relevance of step-by-step innovations is supported by empirical evidence that product market competition can be positively related to productivity growth (see Nickell (1999) and Bassanini and Ernst (2002)) where the relationship might become negative for high levels of competition (see Aghion et al. (2002)).

Building on a model with step-by-step innovations we show in this paper that dismissal costs spur innovation if product markets are not too competitive: technologically more advanced firms endogenously exit with smaller probability so that there is a dynamic incentive to innovate in order to decrease the expected value of the dismissal cost. But dismissal costs decrease the absolute asset value of the firm and can induce exit of whole industries, especially if the absolute value is already low because of intense competition. These opposite effects and their dependence on the policy mix of collective dismissal cost and product market regulation explain why empirical studies have difficulties to detect a robust negative effect of EPL on innovation. In particular, the model can explain why some studies find a positive effect of EPL on innovation for certain industries.

Collective dismissal costs clearly have an adverse effect on innovations if markets are perfect and complete. In our modeling framework this is not the case because of product market imperfections: each industry is characterized by a duopoly. This is in the spirit of some related papers on firing cost and growth. Levine and Tyson (1990) argue that higher job security increases employee participation and thus productivity where employers do not offer job security on their own initiative because of adverse selection. Offering more security compared to other firms would result in loweffort job applicants (see Levine (1991)). More formally, Fella (2000) shows in a model with search frictions that severance payments increase the firm's willingness to invest in worker's general training: separation is less likely to occur in which case the firm looses all of its investment since the human capital is embodied in the worker. In Fella's model large severance payments or consensual layoff agreements induce firms to bargain efficiently over the joint payoff from separation. Another 
explanation is put forward by Saint-Paul (2002). In his model production of goods is relatively less risky at late stages of the product cycle. Saint-Paul shows that firing costs decrease R\&D activity for new goods, the "primary" innovation, whereas they increase R\&D for imitation of mature goods, the "secondary" innovation. However, all these explanations are at odds with empirical evidence that product market competition tends to be positively related to innovation or productivity growth. More variability of product demand and resulting layoffs decrease employee participation according to Levine and Tyson (1990) so that an increase in product market competition lowers productivity. In the model of Fella (2000) the joint surplus of the match decreases if product markets are more competitive. As turnover rises in the labor market, firms' investment in general training falls. Finally, in the model of Saint-Paul (2002) higher turnover in the labor market resulting from product market competition or higher production risk decreases R\&D for "primary" innovation in favor of R\&D for "secondary" innovation. Our modeling framework instead is consistent with both pieces of empirical evidence, the possible positive correlation between product market competition or exit costs and innovation.

The rest of the paper is structured as follows. In Section 2 we present the model. In Section 3 we derive the main result that collective dismissal costs spur innovation if product markets are not too competitive. We conclude in Section 4.

\section{$2 \quad$ A model}

The economy has a continuum of production sectors and a continuum of consumers. ${ }^{1}$

Consumers Households with infinite horizon have the preferences

$$
U(C(t), l(t))=\int_{0}^{\infty} e^{-r t}\left[\int_{0}^{1} \ln C_{i}(t) d i-l(t)\right] d t
$$

where $C_{i}$ denotes consumption of goods produced by industry $i, r$ is the market interest rate which equals the discount rate and $l$ denotes the labor supplied by each household. The preferences

\footnotetext{
${ }^{1}$ Production and innovation are modelled as in Aghion et al. (2001).
} 
imply infinitely elastic labor supply. ${ }^{2} \quad$ Furthermore, log-utility implies that a fixed amount of expenditure is spent on each good. ${ }^{3}$ The household's maximization problem is characterized by the current-value Hamiltonian

$$
\mathcal{H}=\int_{0}^{1} \ln C_{i}(t) d i-l(t)+\zeta(t)\left(w l(t)-\int_{0}^{1} P_{i}(t) C_{i}(t) d i\right)
$$

where $w$ denotes the wage, $P_{i}$ is the price of consumption goods $C_{i}$ and $\zeta$ is the multiplier of the budget constraint. Note that agents do not have access to capital markets. Allowing agents to borrow or save would substantially complicate the model since turnover due to firm exit exposes agents to uncertainty. Given that agents have log-utility, precautionary saving motives would arise. From a technical point of view, the assumption is done for tractability because otherwise the problem would have a state variable, liquid assets, which in general would not allow us to derive the analytic results below. The first-order conditions with respect to $C_{i}(t)$ and $l(t)$ are

$$
\frac{1}{C_{i}(t)}=\zeta(t) P_{i}(t)
$$

and

$$
w=\frac{1}{\zeta(t)} .
$$

Substituting out $\zeta(t)$ and integrating over $i$, we get

$$
w=\int_{0}^{1} P_{i}(t) C_{i}(t) d i=1
$$

where the last equality follows because we normalize expenditure for the goods of each industry to one. Note that the representative agent supplies one unit of labor if all industries produce.

The goods produced by the two firms in each industry are assumed to be imperfectly substitutable in the utility function. The composite consumption good of each industry is characterized

\footnotetext{
${ }^{2}$ As pointed out by Aghion et al. (1997) inelastic labor supply will lower the effects of, e.g., product market competition on innovations because wages rise as employment does which lowers the rents obtained by innovating.

${ }^{3}$ Note that strictly speaking we need to define consumer utility as $\ln \left(C_{i}+\underline{c}\right), \underline{c}>0$, for marginal utility to be well defined if the whole industry $i$ stops producing (see below). Alternatively, we could restrict the support of the industry shocks to prevent this from happening.
} 
by

$$
C_{i}=g_{i}\left(c_{a}, c_{b}\right)=\left(c_{a}^{\alpha_{i}}+c_{b}^{\alpha_{i}}\right)^{\frac{1}{\alpha_{i}}}
$$

where consumption goods of the two firms are $c_{a}$ and $c_{b}$, respectively. Although $\alpha_{i}$ is really a taste parameter, it relates to standard measures of competition. E.g., a higher $\alpha_{i}$ implies a higher elasticity of demand and less market power. Note that in the limit case of $\alpha=1$ the goods of the two firms are perfect substitutes. We assume for simplicity that competition is the same across industries, i.e., $\alpha=\alpha_{i} \in(0 ; 1)$. Then the problem structure is symmetric for all industries so that we drop the industry index $i$ in the rest of the paper.

The problem's structure allows two-stage budgeting so that consumption for each of the two goods in every industry is determined by the following maximization problem:

$$
\max _{c_{j}} g\left(c_{a}, c_{b}\right)
$$

s.t.

$$
p_{a} c_{a}+p_{b} c_{b}=1 \text {. }
$$

This implies that

$$
c_{a}=\frac{p_{a}^{\frac{1}{\alpha-1}}}{p_{a}^{\frac{\alpha}{\alpha-1}}+p_{b}^{\frac{\alpha}{\alpha-1}}}
$$

and

$$
c_{b}=\frac{p_{b}^{\frac{1}{\alpha-1}}}{p_{a}^{\frac{\alpha}{\alpha-1}}+p_{b}^{\frac{\alpha}{\alpha-1}}},
$$

where $p_{a}$ denotes the price of the good produced by firm $a$.

Producers There are barriers to entry since the market of each industry is characterized by a duopoly. As in Aghion et al. (2001), two firms engage in an infinitely repeated duopoly game in which they perform R\&D and then set prices in Bertrand competition. Rents occur although the production function is assumed to have constant returns. Consequently, unit costs do not depend on the quantities produced. This assumption is important because with fixed costs the most costefficient way to produce would be achieved with one firm only. Collective dismissal costs would 
have an unambiguously negative effect on innovations in such a model since such costs decrease monopoly rents. Instead, this is not necessarily the case in the duopoly model as we will see below.

Markets clear so that

$$
c_{j}=x_{j},
$$

where $x_{j}$ is the amount of output produced by each firm $j=a, b$. The elasticity of demand (defined as a positive number) corresponding to the demand functions (2) and (3) derived above is

$$
\eta_{j}=\frac{1-\alpha \lambda_{j}}{1-\alpha}
$$

The revenue, $\lambda_{j} \equiv p_{j} x_{j}$, can be written as

$$
\lambda_{j}=\frac{p_{j}^{\frac{\alpha}{\alpha-1}}}{p_{a}^{\frac{\alpha}{\alpha-1}}+p_{b}^{\frac{\alpha}{\alpha-1}}},
$$

where $\lambda_{a}+\lambda_{b}=1$ given our normalization of industry expenditure.

We assume that each firm can adjust its labor force without cost unless it exits the industry. These costs are best interpreted as collective dismissal or other exit costs. In particular, firms can adjust their labor force marginally without cost as they become relatively more or less efficient with respect to their competitor. Adjustment costs such as firing costs for marginal labor force adjustment would not allow us to derive analytic results in general because the revenue function would need to be conditioned on the state variable $l$. In future research we plan to analyze the role of marginal adjustment cost numerically.

We assume that the production function has constant returns

$$
x_{j}=\left(\rho_{j}\right)^{-1} l_{j}
$$

where equation (1) implies that the cost of every production unit in firm $j$ is $\rho_{j}$. Given these assumptions and equation (4), the revenue-maximizing price of firm $j$ is

$$
p_{j}=\frac{\eta_{j}}{\eta_{j}-1} \rho_{j}=\frac{1-\alpha \lambda_{j}}{\alpha\left(1-\lambda_{j}\right)} \rho_{j} .
$$


Finally, profits are determined by

$$
\pi_{j}=\frac{\lambda_{j}}{\eta_{j}}=\frac{\lambda_{j}(1-\alpha)}{1-\alpha \lambda_{j}}
$$

where we use equation (4) for the second equality.

As shown by Aghion et al. (2001), equations (5), (7) and (8) can solved for unique equilibrium prices, revenues and profits which depend on the relative cost

$$
z_{j} \equiv \frac{\rho_{j}}{\rho_{-j}}
$$

For given $\alpha$, the equilibrium profit of firm $j$ negatively depends on the relative cost $z_{i}$ since the demand for the industry good is unit-elastic. The absolute cost level does not matter for profits. Moreover,

$$
\lim _{z_{j} \rightarrow 0} \pi_{j}\left(z_{j}\right)=1
$$

i.e., a firm's profit equals total revenue if the competitor is not competitive at all. In this case the firm sells the intermediate good at a finite but very high price and extracts all revenues at infinitesimal cost. Moreover, note that revenues and profit flows do not depend on the relative technology $z$ if the goods of the two firms are not substitutable at all, i.e., for $\alpha=0$

$$
\pi_{j}(\alpha=0)=\frac{1}{2}
$$

Process innovations Each sector is assumed to be a duopoly also in innovations. The effort for innovations is assumed to depend on the current state of technology which implies that we search for symmetric stationary equilibria in Markov strategies. We derive results for the case of very large innovations in order to convey the main message as simple as possible. The results can be generalized, however. As shown by Aghion et al. (2001) small innovations decrease the appropriability effect present in Schumpeterian models. Because of the appropriability effect, policies that decrease absolute rents are bad for growth in the classic Schumpeterian model of creative destruction.

If a firm innovates, its input requirement for production falls by the factor $\gamma^{-1}, \gamma>1$. Hence, the relative cost of the technological leader being one step ahead is $z=\gamma^{-1}$. In the case of very 
large innovations the technology leader does not innovate (this is indeed optimal if $\gamma \rightarrow \infty$ because $z=\gamma^{-1}$ and equation (10) imply that profits cannot be increased further by innovation). Hence, a technology leader is at most one step ahead on the technology frontier. The relative position of each firm can be summarized by the subscripts $k=\{1,0,-1\}$ which denote the technology leader, neck-and-neck firms and the technology laggard, respectively. Step-by-step innovations mean that a technology laggard first has to catch up before he can become a technology leader. Employing $\frac{\beta q^{2}}{2}$ units of labor, $\beta>0$, a firm moves one step forward on the technology frontier with the endogenous Poisson hazard rate $q_{k}$. Because of very large innovations the technology leader does not exert any research effort, i.e., $q_{1}=0$. The technological follower catches up with the leader at rate $q_{-1}$. If this happens, firms are neck-and-neck and exert research effort $q_{0}$ which is then also the endogenous Poisson hazard rate for each firm to become a technology leader.

Profit shocks and collective dismissal cost We assume that every industry is exposed to an i.i.d. exogenous profit shock $\varepsilon$ which hits each industry with Poisson probability $\phi .{ }^{4}$ This shock can be interpreted as an unexpected change of an industry's business conditions such as costs of law suits resulting from unforeseen consequences of new inventions or government subsidies for certain industries. ${ }^{5}$ We let this shock be uniformly distributed in the interval $[\underline{\varepsilon} ; \bar{\varepsilon}]$ normalizing the expected value to $E(\varepsilon)=0$ and denoting the cumulative distribution function with $G(\varepsilon)$. The support of the distribution is such that firms close down their business should they be exposed to an adverse enough shock. The explicit condition will be mentioned below. Moreover, we allow for exogenous churning with Poisson hazard $\xi$. Exogenous churning secures that firms exit and reenter in equilibrium. Once a firm stops operations, it can restart production in the subsequent

\footnotetext{
${ }^{4}$ This assumption makes the model's solution substantially easier because the difference of the asset value of firms within an industry is not stochastic.

${ }^{5}$ Government subsidies are financed lump-sum without adding further distortions. Alternatively, one could assume firm-specific taste shocks which are such that profits increase by the same amount, independent of the position on the technology frontier.
} 
periods if business conditions are more favorable, i.e., if a larger $\varepsilon$ is realized. ${ }^{6}$ In the case of exogenous churning, firms immediately reenter (or the firm is replaced by an identical firm). This set-up allows us to preserve the duopoly structure of the industries and simplifies the analysis considerably. Letting the industry market structure be endogenous is a challenging task for future research.

Dismissal costs are not neutral for firms since they cannot pass on the cost to the workers. If the realization of $\varepsilon$ is smaller than the critical value $\varepsilon_{k}$, all workers are fired and firms incur wasteful collective dismissal costs of size $\delta$. The critical value $\varepsilon_{k}$ depends on the firms' position on the technology frontier. Denoting the asset value of the firm with $V$, firms fire if

$$
V_{k}(\varepsilon) \leq-\delta
$$

where the subscript $k \in\{1,0,-1\}$ denotes the relative position on the technology frontier. Since $V_{1}>V_{0}>V_{-1}$ and $V_{k}$ depends positively on $\varepsilon$, it follows that $\varepsilon_{1}<\varepsilon_{0}<\varepsilon_{-1}<0$ (explicit expressions for $V_{k}$ and $\varepsilon_{k}$ are given below). Technologically more advanced firms close down if relatively more adverse shocks occur. Hence, the probability of exit decreases as firms advance on the technology frontier: $G\left(\varepsilon \leq \varepsilon_{1}\right)<G\left(\varepsilon \leq \varepsilon_{0}\right)<G\left(\varepsilon \leq \varepsilon_{-1}\right)$.

Note that the same number of workers is employed over time: the continuum of industries implies that the law of large numbers holds. The same mass of firms exits and reenters at every point in time. Labor saving innovations do not affect labor demand because innovations are passed on to prices and product demand is unit elastic. Unemployment can arise if whole sectors shut down. The level of unemployment depends on the mass of industries exiting and reentering. However, given that we do not allow for changes in market structure, it is clear that our model is not really useful to analyze employment effects of product market regulation or collective dismissal costs. Thus, we concentrate on the effect on innovation in the analysis below.

\footnotetext{
${ }^{6}$ Since we look at the case of very large innovations so that the technology leader never innovates, we can neglect changes of the relative technology position while one firm is out of business. Firms that are out of business do not innovate by definition (they would not be considered out-of-business otherwise).
} 
Asset value of the firm The asset value of the firm $V_{k}$ in the three states satisfies the following equations for small time intervals which we will explain below in some detail:

$$
\begin{aligned}
& r V_{1}(\varepsilon)=\pi_{1}+\varepsilon+q_{-1}\left(V_{0}(\varepsilon)-V_{1}(\varepsilon)\right) \\
& +\phi\left(\int_{\varepsilon_{-1}}^{\bar{\varepsilon}} V_{1}(y) d G(y)+\int_{\varepsilon_{1}}^{\varepsilon_{-1}} V_{m}(y) d G(y)+G\left(\varepsilon \leq \varepsilon_{1}\right)(-\delta)-V_{1}(\varepsilon)\right)+\xi\left(-V_{1}(\varepsilon)\right), \\
& r V_{0}(\varepsilon)=\pi_{0}+\varepsilon+q_{0}\left(V_{1}(\varepsilon)-V_{0}(\varepsilon)\right)+\stackrel{\substack{r_{i v a l}^{\prime} s R \& D \\
q_{0}}}{\left(V_{-1}(\varepsilon)-V_{0}(\varepsilon)\right)-\frac{\beta\left(q_{0}\right)^{2}}{2}} \\
& \quad+\phi\left(\int_{\varepsilon_{0}}^{\bar{\varepsilon}} V_{0}(y) d G(y)+G\left(\varepsilon \leq \varepsilon_{0}\right)(-\delta)-V_{0}(\varepsilon)\right)+\xi\left(-V_{0}(\varepsilon)\right)
\end{aligned}
$$

and

$$
\begin{aligned}
r V_{-1}(\varepsilon)= & \pi_{-1}+\varepsilon+q_{-1}\left(V_{0}(\varepsilon)-V_{-1}(\varepsilon)\right)-\frac{\beta\left(q_{-1}\right)^{2}}{2} \\
& +\phi\left(\int_{\varepsilon_{-1}}^{\bar{\varepsilon}} V_{-1}(y) d G(y)+G\left(\varepsilon \leq \varepsilon_{-1}\right)(-\delta)-V_{-1}(\varepsilon)\right)+\xi\left(-V_{-1}(\varepsilon)\right) .
\end{aligned}
$$

E.g., in equation (15) the asset value of a technology laggard contains profit flows $\pi_{-1}$ and the change of the firm's asset value moving one step ahead on the technology frontier, $V_{0}-V_{-1}$, which happens with probability $q_{-1}$. There is a flow cost of $\frac{\beta\left(q_{-1}\right)^{2}}{2}$ for the labor used for process innovation. Furthermore, the firm's asset value changes with Poisson probability $\phi$ because of profit shocks. With probability $G\left(\varepsilon \leq \varepsilon_{-1}\right)$ the firm exits and incurs the collective dismissal cost $-\delta$. Finally, with Poisson probability $\xi$ natural attrition dissolves the match between workers and the firm without cost so that the asset value of the firm falls to $0 .^{7}$

The intuition for equation (14) is analogous. Note in equation (13) that the technology leader has no incentive to innovate because we assume very large innovations. ${ }^{8}$ Moreover, the leader can

\footnotetext{
${ }^{7}$ Note that exogenous churning does not affect the asset value of the competitor. This is because we have assumed above that exogenous churning leaves the duopoly structure unchanged (firms reenter immediately or are replaced by identical firms). This assumption simplifies the algebra but is not crucial for the results.

${ }^{8}$ If innovations are small instead, dismissal costs imply an additional incentive to innovate also for the technology leader.
} 
become monopolist for a small time interval (we use the subscript $m$ for this case). This event occurs, i.e., if $\varepsilon_{1} \leq \varepsilon \leq \varepsilon_{-1}$ and the probability of this event is $G\left(\varepsilon_{1} \leq \varepsilon \leq \varepsilon_{-1}\right)$. In this case the industry shock is such that the technology leader continues to produce whereas the technology laggard decides to stop production and innovation. The profits of the monopolist are given by

$$
\pi_{m}=\lim _{\gamma \rightarrow \infty} \pi_{1}=1
$$

The monopolist is able to extract all consumer expenditure (which we normalized to 1 ). The asset value of the monopolist leader is

$r V_{m}(\varepsilon)=\pi_{m}+\varepsilon+\phi\left(\int_{\varepsilon_{-1}}^{\bar{\varepsilon}} V_{1}(\varepsilon) d G(\varepsilon)+\int_{\varepsilon_{1}}^{\varepsilon_{-1}} V_{m}(\varepsilon) d G(\varepsilon)+G\left(\varepsilon \leq \varepsilon_{1}\right)(-\delta)-V_{m}(\varepsilon)\right)+\xi\left(-V_{m}(\varepsilon)\right)$.

Note that compared with equation (13), the monopolist technology leader is better off because he does not face the immediate risk of becoming a neck-and-neck firm given that his competitor is out of business and does not engage in process innovation.

Exit thresholds As mentioned above, industries are characterized by a duopoly. We assume that the entry cost $C(\alpha)$ is such that the technology laggard is just indifferent ex ante whether to enter the market or not:

$$
V_{-1}(0)=C(\alpha)
$$

The entry cost has to fall as product markets become more competitive so that the technology laggard remains indifferent although his profit flows fall. Note that $\varepsilon$ affects the whole industry so that

$$
\Delta_{k} \equiv V_{k}(\varepsilon)-V_{k-1}(\varepsilon)
$$

does not depend on $\varepsilon$. Using equations (12) and (17) we find:

Result 1: The exit thresholds are

$$
\varepsilon_{-1}=-(r+\phi+\xi)(C+\delta)
$$




$$
\varepsilon_{0}=-(r+\phi+\xi)\left(C+\delta+\Delta_{0}\right),
$$

and

$$
\varepsilon_{1}=-(r+\phi+\xi)\left(C+\delta+\Delta_{0}+\Delta_{m}\right),
$$

where $\Delta_{m} \equiv V_{m}-V_{0}$.

Proof: see the Appendix.

Equation (20) follows because the technology leader only exits when the laggard is already out of business. Intuitively, the exit thresholds negatively depend on the collective dismissal and entry cost. Since $\Delta_{0}>0$ and $\Delta_{m}>0$, equations (18) $(20)$ imply that

$$
0>\varepsilon_{-1}>\varepsilon_{0}>\varepsilon_{1} .
$$

Technologically more advanced firms exit if shocks are relatively more adverse.

Innovation effort As mentioned above, innovations are very large so that the technology leader will not exert any innovation effort:

$$
q_{1}=0 .
$$

Differentiating equations $(14)^{\sim}(15)$ with respect to $q_{0}$ and $q_{-1}$, respectively, we find that

$$
q_{0}=\frac{\Delta_{1}}{\beta}
$$

and

$$
q_{-1}=\frac{\Delta_{0}}{\beta} .
$$

Innovation efforts positively depend on the increase of the asset value as firms improve their relative position on the technology frontier. We now have all the ingredients to analyze the effects of collective dismissal costs on innovation. 


\section{Collective dismissal costs and innovation}

The model can be solved explicitly applying the method of undetermined coefficients but the solution is too messy to add to the intuition. Instead, using equations $(13)^{\sim}(16)$, we find that

Result 2: The model can be characterized in terms of $\Delta_{k}$ by the two equations

$$
\begin{aligned}
F_{1}\left(\Delta_{0}, \Delta_{1}, \delta\right) & \equiv \frac{\Delta_{1}^{2}}{2 \beta}+\left(r+\phi \frac{\bar{\varepsilon}-(r+\phi+\xi)\left(C+\delta+\Delta_{0}\right)-\frac{\Delta_{0}^{2}}{\beta}}{2 \bar{\varepsilon}}+\xi\right) \Delta_{1} \\
& -\left(\pi_{1}-\pi_{0}\right)-\frac{1}{2} \phi \frac{\left(r+\phi+\xi+\frac{\Delta_{0}}{\beta}\right)^{2}}{2 \bar{\varepsilon}} \Delta_{1}^{2}=0
\end{aligned}
$$

and

$$
\begin{aligned}
F_{0}\left(\Delta_{0}, \Delta_{1}, \delta\right) \equiv & \frac{\Delta_{0}^{2}}{2 \beta}+\left(r+\phi \frac{\bar{\varepsilon}-(r+\phi+\xi)\left(C+\delta+\Delta_{0}\right)}{2 \bar{\varepsilon}}+\xi\right) \Delta_{0} \\
& -\left(\pi_{0}-\pi_{-1}\right)-\frac{\Delta_{1}^{2}}{2 \beta}+\frac{\Delta_{0} \Delta_{1}}{\beta}-\frac{1}{2} \phi \frac{(r+\phi+\xi)^{2}}{2 \bar{\varepsilon}} \Delta_{0}^{2}=0
\end{aligned}
$$

Proof: see the Appendix.

Subtracting equation (25) from (24) we can show that analogous to Aghion et al. (2001):

Result 3: Innovation efforts are strongest if firms are neck-and-neck, i.e.,

$$
\Delta_{1}>\Delta_{0}
$$

Proof: see the Appendix.

Because of equations (22) and (23), $\Delta_{1}>\Delta_{0}$ implies that innovation efforts are strongest if firms are neck-and-neck.

The system of equations

$$
F \equiv\left[\begin{array}{l}
F_{1} \\
F_{0}
\end{array}\right]=0
$$


implicitly determines $\Delta_{1}$ and $\Delta_{0}$ as a function of $\delta$. Note that, as in Aghion et al. (2001), $\Delta_{1}$ and $\Delta_{0}$ (and thus also the innovation efforts $q_{1}$ and $q_{0}$ ) depend positively on relative profits $\pi_{1}-\pi_{0}$ and $\pi_{0}-\pi_{-1}$. Stochastic shocks and collective dismissal costs add dynamic incentives to innovate. To illustrate this we show the following.

Result 4: Collective dismissal costs result in additional incentives to innovate for the technology laggard because

$$
\int_{\varepsilon_{0}}^{\varepsilon_{-1}} V_{0}(y) d G(y)+\frac{\varepsilon_{-1}-\varepsilon_{0}}{2 \bar{\varepsilon}} \delta=\frac{1}{2} \frac{(r+\phi+\xi)^{2}}{2 \bar{\varepsilon}} \Delta_{0}^{2}>0,
$$

and for the neck-and-neck firm because

$$
\int_{\varepsilon_{1}}^{\varepsilon_{0}} V_{m}(y) d G(y)+\frac{\varepsilon_{0}-\varepsilon_{1}}{2 \bar{\varepsilon}} \delta=\frac{1}{2} \frac{\left(r+\phi+\xi+\frac{\Delta_{0}}{\beta}\right)^{2}}{2 \bar{\varepsilon}} \Delta_{1}^{2}>0 .
$$

Proof: see the Appendix.

Expressions (27) and (28) are very similar. The additional term $\Delta_{0} / \beta$ in the numerator of (28) results because the technology leader can become monopolists in case of which he does not face competition. More importantly, both expressions show that technologically more advanced firms do not fire in the interval $\left[\varepsilon_{k+1} ; \varepsilon_{k}\right]$ so that innovation has the additional benefit to decrease the expected firing cost by

$$
\frac{\varepsilon_{k}-\varepsilon_{k+1}}{2 \bar{\varepsilon}} \delta
$$

where we use the assumption of a uniform distribution. The additional benefit more than compensates the lower asset value due to the adverse shocks since in the interval $\left[\varepsilon_{k+1} ; \varepsilon_{k}\right], V_{k+1} \geq-\delta$. Note that the additional benefit of innovation does not directly depend on $\delta$ because $V_{k}$ is linear in $\varepsilon$. Thus, as long as firms remain in business, it is irrelevant that higher collective dismissal costs lower the absolute value of $V_{k}$. All that matters is the difference between the exit thresholds. Collective dismissal costs matter directly, however: such costs lower the effective discount rate which, for example, for neck-and-neck firms is defined as

$$
r+\phi G\left(\varepsilon \leq \varepsilon_{0}\right)+\xi=r+\phi\left(\frac{\bar{\varepsilon}-(r+\phi+\xi)\left(C+\delta+\Delta_{0}\right)}{2 \bar{\varepsilon}}\right)+\xi
$$


where we use equation (19) and the assumption of a uniform distribution. The technology leader's effective discount rate is even smaller because he can become monopolist if the laggard stops production and in this case there is no risk of catching-up. A smaller effective discount rate increases the incentives to innovate because firms expect to benefit relatively longer from the successful innovation.

Before we implicitly differentiate the system of equations $F$ to derive the effect of exit costs on innovation, we derive the growth rate implied by the innovation efforts in each industry.

Result 5: The economy grows at rate

$$
\begin{aligned}
g & =\frac{2 G\left(\varepsilon \geq \varepsilon_{0}\right) q_{0} G\left(\varepsilon \geq \varepsilon_{-1}\right) q_{-1}}{2 G\left(\varepsilon \geq \varepsilon_{0}\right) q_{0}+G\left(\varepsilon \geq \varepsilon_{-1}\right) q_{-1}} \ln \gamma \\
& =\frac{2 \Delta_{0} \Delta_{1}\left(\bar{\varepsilon}+(r+\phi+\xi)\left(C+\delta+\Delta_{0}\right)\right)}{2 \beta \Delta_{1} \frac{\bar{\varepsilon}+(r+\phi+\xi)\left(C+\delta+\Delta_{0}\right)}{\bar{\varepsilon}+(r+\phi+\xi)(C+\delta)}+\Delta_{0}} \ln \gamma .
\end{aligned}
$$

Proof: see the Appendix.

Moreover, one can show that

$$
\frac{\partial g}{\partial \Delta_{k}}>0 .
$$

Growth is higher if firms engage in more process innovations (see equations (22) and (23)).

We now can state the main result of this paper.

Result 6: Collective dismissal cost can increase process innovations $q_{k}$ and thus growth $g$ if $\bar{\varepsilon}$ is large enough and $\alpha>0$.

Proof: see the Appendix.

The intuition is that stochastic profit shocks make technologically more advanced firms relatively better off because they stop production with a smaller probability (as shown in Result 4). As we have seen above, technologically more advanced firms have smaller expected firing costs. The size of this effect does not directly depend on $\delta$ in our model (see equation (27)). However, in equilibrium the size of the effect increases in $\delta$ as long as $\partial \Delta_{k} / \partial \delta>0$. Moreover, the effective discount rate is smaller for technologically advanced firms. The size of this effect increases in $\delta$. 
The sufficient condition for Result 6 has an intuitive interpretation: $\bar{\varepsilon}$ needs to be large enough, i.e., a sufficient amount of uncertainty is necessary. More uncertainty increases the probability mass of shocks for which firms need to close down and thus increase the expected exit cost. Technologically more advanced firms are only better off, however, if there is at least some competition, $\alpha>0$. If $\alpha=0$, profit flows and thus also the exit thresholds $\varepsilon_{k}$ are the same so that all firms exit with the same probability (see equation $(11)$ ). Moreover, $V_{-1}(\delta, \alpha)$ is a negative function of both $\delta$ and $\alpha$. Thus, one the one hand, if the rents in the market are small due to intense competition and/or high exit costs, the technology laggards can be driven out of business and only one firm remains producing. In this case, there will be no innovations. On the other hand, $\Delta_{1}$ and $\Delta_{0}$ can increase in $\alpha$ so that exit thresholds differ relatively more and the positive effect of collective dismissal costs on innovation becomes more pronounced. Thus, exit costs can spur innovation and some competition amplifies this effect but rents need not be too small and/or exit costs not too high. The policy mix of exit costs and product market competition, captured by the parameters $(\delta, \alpha)$ in our model, is an important determinant of the effects of exit costs on innovation.

Dismissal costs can spur growth for two reasons. First innovation efforts increase and second the fraction of firms that potentially innovate increases because stopping production is relatively more costly. However, the effect of exit costs on growth should not be taken at face value since we abstract from the effect of exit costs on firm entry by assuming a stable duopoly structure.

\section{Conclusion and Further Research}

Our model shows that collective dismissal costs can spur innovation if product market competition is not too intense: technologically more advanced firms endogenously exit with smaller probability so that there is a dynamic incentive to innovate in order to decrease the expected value of the dismissal cost. This mechanism can explain why empirical studies find a positive relationship between EPL and innovation for some industries whereas the effect is negative for others. The model does not allow, however, to draw conclusions about growth in general. The model is partial 
in an important respect because we do not fully analyze entry and exit decisions of firms so that the results apply to incumbent firms. It would be interesting to extend the model in future research to allow for endogenous changes in the industry structure. Furthermore, a disaggregate empirical analysis of process innovation, exploiting variation across sectors, countries and time with respect to competition and employment protection, could shed further light on the mechanisms at work. 


\section{Appendix}

\section{Proof of Result 1:}

Equations $(13)^{\sim}(16)$ can be solved by applying the method of undetermined coefficients. We guess the solution

$$
V_{k}(\varepsilon)=b_{k} \pi_{k}+c_{k} \varepsilon+d_{k} .
$$

Plugging this guess into equations $(13)^{\sim}(16)$, we get a system of 12 equations in 12 unknowns. Although the general solution is messy, the coefficients $c_{k}$ are determined by the following subset of equations:

$$
\begin{aligned}
& \left(r+\phi+\xi+q_{-1}\right) c_{-1} \varepsilon=\varepsilon+q_{-1} c_{0} \varepsilon \\
& \left(r+\phi+\xi+q_{-1}\right) c_{1} \varepsilon=\varepsilon+q_{-1} c_{0} \varepsilon
\end{aligned}
$$

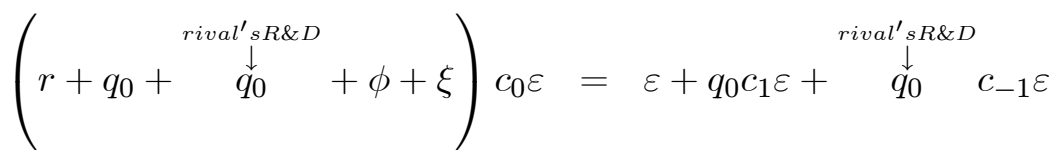

$$
\begin{aligned}
& (r+\phi+\xi) c_{m} \varepsilon=\varepsilon .
\end{aligned}
$$

The solution is

$$
c_{k}=c=(r+\phi+\xi)^{-1} .
$$

Given that the solution takes the form of the guess mentioned above,

$$
V_{k}\left(\varepsilon_{k}\right)-V_{k}(0)=(r+\phi+\xi)^{-1} \varepsilon_{k} .
$$

At the same time equations (12) and (17) imply that

$$
V_{-1}\left(\varepsilon_{-1}\right)-V_{-1}(0)=-(C+\delta) .
$$

Thus,

$$
\varepsilon_{-1}=-(r+\phi+\xi)(C+\delta) .
$$

Given that the shock $\varepsilon$ hits the whole industry,

$$
V_{0}(0)-V_{-1}(0)=\Delta_{0}
$$


does not depend on $\varepsilon$. Using equation (30) and adding and subtracting $V_{-1}(0)$ we get

$$
V_{0}\left(\varepsilon_{0}\right)-V_{0}(0)+V_{-1}(0)-V_{-1}(0)=(r+\phi+\xi)^{-1} \varepsilon_{0}
$$

Using equations (12), (17) and (31), this implies that

$$
\varepsilon_{0}=-(r+\phi+\xi)\left(C+\delta+\Delta_{0}\right)
$$

The derivation of $\varepsilon_{1}$ is analogous

\section{Proof of Result 2:}

Subtracting equation (14) from (13), (14) from (16) and (15) from (14), using the assumption of the uniform distribution and rearranging, we find that

$$
\begin{aligned}
\left(r+q_{0}+q_{-1}+\phi\left(1-\frac{\bar{\varepsilon}-\varepsilon_{-1}}{2 \bar{\varepsilon}}\right)+\xi\right) \Delta_{1}= & \pi_{1}-\pi_{0}+q_{0} \Delta_{0}+\frac{\beta\left(q_{0}\right)^{2}}{2} \\
& +\phi\left(\frac{\varepsilon_{-1}-\varepsilon_{0}}{2 \bar{\varepsilon}} \Delta_{m}+\int_{\varepsilon_{1}}^{\varepsilon_{0}} V_{m}(y) d G(y)+\frac{\varepsilon_{0}-\varepsilon_{1}}{2 \bar{\varepsilon} \delta),}\right. \\
\left(r+\phi\left(1-\frac{\varepsilon_{-1}-\varepsilon_{0}}{2 \bar{\varepsilon}}\right)+\xi\right) \Delta_{m}= & \pi_{m}-\pi_{0}+q_{0}\left(\Delta_{0}-\Delta_{1}\right)+\frac{\beta\left(q_{0}\right)^{2}}{2} \\
& +\phi\left(\frac{\bar{\varepsilon}-\varepsilon_{-1}}{2 \bar{\varepsilon}} \Delta_{1}+\int_{\varepsilon_{1}}^{\varepsilon_{0}} V_{m}(y) d G(y)+\frac{\varepsilon_{0}-\varepsilon_{1}}{2 \bar{\varepsilon}} \delta\right),
\end{aligned}
$$

and

$$
\begin{aligned}
\left(r+q_{-1}+q_{0}+\phi\left(1-\frac{\bar{\varepsilon}-\varepsilon_{0}}{2 \bar{\varepsilon}}\right)+\xi\right) \Delta_{0}= & \pi_{0}-\pi_{-1}+q_{0} \Delta_{1}-\frac{\beta\left(q_{0}\right)^{2}}{2}+\frac{\beta\left(q_{-1}\right)^{2}}{2} \\
& +\phi\left(\int_{\varepsilon_{0}}^{\varepsilon_{-1}} V_{0}(y) d G(y)+\frac{\varepsilon_{-1}-\varepsilon_{0}}{2 \bar{\varepsilon}} \delta\right)
\end{aligned}
$$

Subtracting equation (33) from (32) and using that $\pi_{m}-\pi_{1} \approx 0$ for the case of very large innovations,

$$
\Delta_{m}=\frac{r+\phi+\xi+q-1}{r+\phi+\xi} \Delta_{1}
$$

Moreover, we can express the integrals in terms of $\Delta_{k}$ exploiting that $V(\varepsilon)$ is linear in $\varepsilon$ and the density is constant for the uniform distribution. In graphical terms, the integral can be calculated by subtracting a 
triangle from a rectangle. Using equations $(12),(18)^{\sim}(23),(30)$ and (35) we find that

$$
\begin{aligned}
\int_{\varepsilon_{1}}^{\varepsilon_{0}} V_{m}(y) d G(y) & =\frac{\left(\varepsilon_{0}-\varepsilon_{1}\right)}{2 \bar{\varepsilon}}\left[V_{m}\left(\varepsilon_{1}\right)-\frac{1}{2}\left(V_{m}\left(\varepsilon_{1}\right)-V_{m}\left(\varepsilon_{0}\right)\right)\right] \\
& =-\frac{r+\phi+\xi+\frac{\Delta_{0}}{\beta}}{2 \bar{\varepsilon}} \Delta_{1}\left(\delta-\frac{1}{2}\left(r+\phi+\xi+\frac{\Delta_{0}}{\beta}\right) \Delta_{1}\right) .
\end{aligned}
$$

Similarly,

$$
\begin{aligned}
\int_{\varepsilon_{0}}^{\varepsilon_{-1}} V_{0}(y) d G(y) & =\frac{\left(\varepsilon_{-1}-\varepsilon_{0}\right)}{2 \bar{\varepsilon}}\left[V_{0}\left(\varepsilon_{0}\right)-\frac{1}{2}\left(V_{0}\left(\varepsilon_{0}\right)-V_{0}\left(\varepsilon_{-1}\right)\right)\right] \\
& =-\frac{r+\phi+\xi}{2 \bar{\varepsilon}} \Delta_{0}\left(\delta-\frac{1}{2}(r+\phi+\xi) \Delta_{0}\right) .
\end{aligned}
$$

Substituting equations $(35)^{\sim}(37)$ and $(18)^{\sim}(23)$ into equations (32) and (34) and rearranging, we get equations $(24)$ and (25).

\section{Proof of Result 3:}

Subtracting equation (25) from (24) yields

$$
\begin{aligned}
& \frac{\Delta_{1}^{2}-\Delta_{0}^{2}}{2 \beta}+\left(r+\phi\left(\frac{\bar{\varepsilon}-(r+\phi+\xi)\left(C+\delta+\Delta_{0}\right)}{2 \bar{\varepsilon}}\right)+\xi\right)\left(\Delta_{1}-\Delta_{0}\right) \\
+ & \frac{\Delta_{1}\left(\Delta_{1}-\Delta_{0}\right)}{2 \beta}-\frac{1}{2} \phi \frac{(r+\phi+\xi)^{2}}{2 \bar{\varepsilon}}\left(\Delta_{1}^{2}-\Delta_{0}^{2}\right) \\
= & \phi \frac{\Delta_{0}^{2}}{2 \beta \bar{\varepsilon}} \Delta_{1}+\frac{1}{2} \frac{\phi}{2 \bar{\varepsilon}}\left(\frac{\Delta_{0}}{\beta}\right)^{2} \Delta_{1}^{2}+\pi_{1}+\pi_{-1}-2 \pi_{0} .
\end{aligned}
$$

The right-hand side of equation (38) is positive because

$$
\Delta_{k}>0
$$

and

$$
\pi_{1}+\pi_{-1}>2 \pi_{0},
$$

where the last inequality is shown in Proposition 1, Aghion et al. (2001).

The left-hand-side of equation (38) is a positive function of $\Delta_{1}-\Delta_{0}$ if

$$
\bar{\varepsilon}>\frac{1}{2} \phi \beta(r+\phi+\xi)^{2} .
$$


Hence,

$$
\Delta_{1}-\Delta_{0}>0
$$

Condition (39) is satisfied as long as $\Delta_{k}$ depends positively on $\pi_{k+1}-\pi_{k}$ in case of which the model's solution is of interest (see equations (24) and (25))

\section{Proof of Result 4:}

Equation (37) in the proof of Result 2 implies that

$$
\int_{\varepsilon_{0}}^{\varepsilon_{-1}} V_{0}(y) d G(y)=-\frac{r+\phi+\xi}{2 \bar{\varepsilon}} \Delta_{0}\left(\delta-\frac{1}{2}(r+\phi+\xi) \Delta_{0}\right) .
$$

Moreover, Result 1 implies that

$$
\frac{\varepsilon_{-1}-\varepsilon_{0}}{2 \bar{\varepsilon}} \delta=\frac{(r+\phi+\xi) \Delta_{0}}{2 \bar{\varepsilon}} \delta .
$$

Hence,

$$
\int_{\varepsilon_{0}}^{\varepsilon_{-1}} V_{0}(y) d G(y)+\frac{\varepsilon_{-1}-\varepsilon_{0}}{2 \bar{\varepsilon}} \delta=\frac{1}{2} \frac{(r+\phi+\xi)^{2}}{2 \bar{\varepsilon}} \Delta_{0}^{2} .
$$

Expression (28) is derived analogously

\section{Proof of Result 5:}

We use the same notation as in Aghion et al. (2001) and adapt their argument to our model. First note that in steady state as many firms have to exit a state on the relative technology frontier as enter the same very state. Let $\mu_{h}$ be the fraction of firms in state $h \in\{\iota, n\}$, where $\iota$ denotes the state in which there is a technology laggard and leader and $n$ denotes the state in which both firms are neck-and-neck. In each of these states firms can stop production. Only the firms in business do innovate. This implies that in steady state

$$
2 \mu_{n} G\left(\varepsilon \geq \varepsilon_{0}\right) q_{0}=\mu_{\iota} G\left(\varepsilon \geq \varepsilon_{-1}\right) q_{-1} .
$$

In state $n$ both neck-and-neck firms engage in process innovation if they do not exit and they are successful with probability $q_{0}$. In state $\iota$ only the technology laggard potentially innovates with probability $q_{-1}$ if he does not exit. Given that $\mu_{n}+\mu_{\iota}=1$, the equation simplifies to

$$
2 \mu_{n} G\left(\varepsilon \geq \varepsilon_{0}\right) q_{0}=\left(1-\mu_{n}\right) G\left(\varepsilon \geq \varepsilon_{-1}\right) q_{-1} .
$$


Aggregate output $Y$ is defined as

$$
\ln Y=\int_{0}^{1} \ln X_{i} d i
$$

where $X_{i}$ is the industry output defined as

$$
X_{i} \equiv\left(x_{i, j}^{\alpha_{i}}+x_{i,-j}^{\alpha_{i}}\right)^{\frac{1}{\alpha_{i}}}
$$

The economy grows at rate

$$
g=\frac{d}{d t} \ln Y
$$

Since $\ln X_{i}$ is exposed to independent and identically distributed shocks, the growth rate equals

$$
g=\lim _{\Delta t \rightarrow \infty} \frac{\Delta \ln X_{i}}{\Delta t}
$$

This growth rate is determined by the asymptotic frequency of firms that advance the industry's frontier technology. Every time this happens the value of $\ln X_{i}$ increases by $\ln \gamma$. In the case of very large innovations only the firms which are neck-and-neck advance the industry's frontier technology. The asymptotic fraction of firms in this state is $\mu_{n}$ and the probability that the technology frontier is advanced is $2 q_{0}$ so that

$$
g=2 \mu_{n} G\left(\varepsilon \geq \varepsilon_{0}\right) q_{0} \ln \gamma=\frac{2 G\left(\varepsilon \geq \varepsilon_{0}\right) q_{0} G\left(\varepsilon \geq \varepsilon_{-1}\right) q_{-1}}{2 G\left(\varepsilon \geq \varepsilon_{0}\right) q_{0}+G\left(\varepsilon \geq \varepsilon_{-1}\right) q_{-1}} \ln \gamma
$$

where the last equality uses equation (40)

\section{Proof of Result 6:}

We derive $\frac{\partial \Delta_{0}}{\partial \delta}$ and $\frac{\partial \Delta_{1}}{\partial \delta}$ by implicit differentiation of the system of equations (24) and (25):

$$
\begin{aligned}
& {\left[\begin{array}{c}
\frac{\partial \Delta_{1}}{\partial \delta} \\
\frac{\partial \Delta_{0}}{\partial \delta}
\end{array}\right]=-\left[\begin{array}{ll}
\frac{\partial F_{1}}{\partial \Delta_{1}} & \frac{\partial F_{1}}{\partial \Delta_{0}} \\
\frac{\partial F_{0}}{\partial \Delta_{1}} & \frac{\partial F_{0}}{\partial \Delta_{0}}
\end{array}\right]^{-1}\left[\begin{array}{c}
\frac{\partial F_{1}}{\partial \delta} \\
\frac{\partial F_{0}}{\partial \delta}
\end{array}\right]} \\
& =-\frac{1}{\frac{\partial F_{1}}{\partial \Delta_{1}} \frac{\partial F_{0}}{\partial \Delta_{0}}-\frac{\partial F_{0}}{\partial \Delta_{1}} \frac{\partial F_{1}}{\partial \Delta_{0}}}\left[\begin{array}{cc}
\frac{\partial F_{0}}{\partial \Delta_{0}} & -\frac{\partial F_{1}}{\partial \Delta_{0}} \\
-\frac{\partial F_{0}}{\partial \Delta_{1}} & \frac{\partial F_{1}}{\partial \Delta_{1}}
\end{array}\right]\left[\begin{array}{c}
\frac{\partial F_{1}}{\partial \delta} \\
\frac{\partial F_{0}}{\partial \delta}
\end{array}\right] \\
& =\frac{1}{\frac{\partial F_{1}}{\partial \Delta_{1}} \frac{\partial F_{0}}{\partial \Delta_{0}}-\frac{\partial F_{0}}{\partial \Delta_{1}} \frac{\partial F_{1}}{\partial \Delta_{0}}}\left[\begin{array}{c}
\frac{\partial F_{1}}{\partial \Delta_{0}} \frac{\partial F_{0}}{\partial \delta}-\frac{\partial F_{0}}{\partial \Delta_{0}} \frac{\partial F_{1}}{\partial \delta} \\
\frac{\partial F_{0}}{\partial \Delta_{1}} \frac{\partial F_{1}}{\partial \delta}-\frac{\partial F_{1}}{\partial \Delta_{1}} \frac{\partial F_{0}}{\partial \delta}
\end{array}\right] \text {. }
\end{aligned}
$$


A sufficient condition for $\frac{\partial \Delta_{i}}{\partial \delta}>0, i=0,1$, is that

$$
\frac{\partial F_{i}}{\partial \delta}<0, \frac{\partial F_{i}}{\partial \Delta_{i}}>0, \frac{\partial F_{j}}{\partial \Delta_{i}}<0
$$

and

$$
\frac{\partial F_{i}}{\partial \Delta_{i}}>\left|\frac{\partial F_{j}}{\partial \Delta_{i}}\right|
$$

where $j \neq i, j=0,1$. It remains to calculate the derivatives $\frac{\partial F_{i}}{\partial \Delta_{j}}$ and $\frac{\partial F_{i}}{\partial \delta}$ and the explicit conditions for the model's parameters.

The derivatives are found to be:

1.

$$
\begin{aligned}
\frac{\partial F_{1}}{\partial \Delta_{1}}= & \frac{\Delta_{1}}{\beta}+\left(r+\phi \frac{\bar{\varepsilon}-(r+\phi+\xi)\left(C+\delta+\Delta_{0}\right)-\frac{\Delta_{0}^{2}}{\beta}}{2 \bar{\varepsilon}}+\xi\right) \\
& -\phi \frac{\left(r+\phi+\xi+\frac{\Delta_{0}}{\beta}\right)^{2}}{2 \bar{\varepsilon}} \Delta_{1}>0,
\end{aligned}
$$

if

$$
\bar{\varepsilon}>\phi \beta \frac{\left(r+\phi+\xi+\frac{\Delta_{0}}{\beta}\right)^{2}}{2} \equiv \varepsilon^{+} .
$$

The inequality is implicit in $\bar{\varepsilon}$ since $\Delta_{0}(\bar{\varepsilon})$. Note that the effective discount rate of the technology leader

$$
r+\phi \frac{\bar{\varepsilon}-(r+\phi+\xi)\left(C+\delta+\Delta_{0}\right)-\frac{\Delta_{0}^{2}}{\beta}}{2 \bar{\varepsilon}}+\xi>0 .
$$

The sufficient condition secures that the first term of the derivative is larger than the last term.

2.

$$
\frac{\partial F_{1}}{\partial \Delta_{0}}=-\Delta_{1} \frac{\phi(r+\phi+\xi)}{\bar{\varepsilon}}\left(\frac{1}{2}+\frac{\Delta_{0}}{\beta(r+\phi+\xi)}\right)-\phi \Delta_{1}^{2} \frac{r+\phi+\xi+\frac{\Delta_{0}}{\beta}}{2 \beta \bar{\varepsilon}}<0 .
$$

3.

$$
\frac{\partial F_{1}}{\partial \delta}=-\frac{\phi(r+\phi+\xi)}{2 \bar{\varepsilon}} \Delta_{1}<0 .
$$

4.

$$
\frac{\partial F_{0}}{\partial \Delta_{1}}=\frac{\Delta_{0}-\Delta_{1}}{\beta}<0
$$

because of Result $3\left(\Delta_{1}>\Delta_{0}\right)$. 
Note that

$$
\left|\frac{\partial F_{0}}{\partial \Delta_{1}}\right|<\frac{\partial F_{1}}{\partial \Delta_{1}}
$$

if

$$
\bar{\varepsilon}>\frac{\phi}{2} \frac{(r+\phi+\xi)\left(C+\delta+\Delta_{0}\right)+\frac{\Delta_{0}^{2}}{\beta}}{r+\frac{\phi}{2}+\xi-\frac{\Delta_{1}-\Delta_{0}}{\beta}} \equiv \varepsilon^{\ddagger}
$$

given the conditions mentioned above. The inequality is implicit in $\bar{\varepsilon}$ since $\Delta_{k}(\bar{\varepsilon})$. The inequality ensures that the second term in brackets of the derivative $\partial F_{1} / \partial \Delta_{1}$ is larger than $\left|\partial F_{0} / \partial \Delta_{1}\right|$.

5.

$\frac{\partial F_{0}}{\partial \Delta_{0}}=\frac{\Delta_{0}}{\beta}+\left(r+\phi\left(\frac{\bar{\varepsilon}-(r+\phi+\xi)\left(C+\delta+\Delta_{0}\right)}{2 \bar{\varepsilon}}\right)+\xi\right)-\frac{\phi(r+\phi+\xi)}{2 \bar{\varepsilon}} \Delta_{0}+\frac{\Delta_{1}}{\beta}-\phi \frac{(r+\phi+\xi)^{2}}{2 \bar{\varepsilon}} \Delta_{0}>0$

if

$$
\bar{\varepsilon}>\phi \beta \frac{(r+\phi+\xi)^{2}+r+\phi+\xi}{4} \equiv \varepsilon^{\dagger} .
$$

Note that $\Delta_{1}>\Delta_{0}$. Given that the effective discount rate is positive (the second term of the derivative), the sufficient condition secures that the first and fourth term are larger than the third and fifth. Moreover,

$$
\left|\frac{\partial F_{1}}{\partial \Delta_{0}}\right|<\frac{\partial F_{0}}{\partial \Delta_{0}}
$$

if

$\bar{\varepsilon}>\frac{\phi(r+\phi+\xi)\left(\frac{1}{2}+\frac{\Delta_{0}}{\beta(r+\phi+\xi)}\right) \Delta_{1}+\phi \Delta_{1}^{2} \frac{r+\phi+\xi+\frac{\Delta_{0}}{\beta}}{2 \beta}+\phi \frac{(r+\phi+\xi)(C+\delta)}{2}+\phi(r+\phi+\xi)\left(1+\frac{r+\phi+\xi}{2}\right) \Delta_{0}}{\frac{\Delta_{0}}{\beta}+\frac{\Delta_{1}}{\beta}+r+\xi+\frac{\phi}{2}} \equiv \varepsilon^{*}$.

The inequality is implicit in $\bar{\varepsilon}$ since $\Delta_{k}(\bar{\varepsilon})$.

6.

$$
\frac{\partial F_{0}}{\partial \delta}=-\frac{\phi(r+\phi+\xi)}{2 \bar{\varepsilon}} \Delta_{0}<0
$$

Thus we have seen that

$$
\frac{\partial \Delta_{i}}{\partial \delta}>0
$$

if

$$
\bar{\varepsilon}>\max \left\{\varepsilon^{+}, \varepsilon^{\dagger}, \varepsilon^{\ddagger}, \varepsilon^{*}\right\} .
$$


Note that this condition is sufficient but not necessary.

We now proceed to show how collective dismissal costs affect growth. Define

$$
\widetilde{q}_{k} \equiv G\left(\varepsilon \geq \varepsilon_{k}\right) q_{k}
$$

so that equation (29) can be rewritten as

$$
g=\frac{2 \widetilde{q}_{0} \widetilde{q}_{-1}}{2 \widetilde{q}_{0}+\widetilde{q}_{-1}} \ln \gamma
$$

Note that

$$
\frac{\partial g}{\partial \widetilde{q}_{k}}>0
$$

Furthermore,

$$
\frac{\partial \widetilde{q}_{k}}{\partial \delta}>0
$$

if

$$
\frac{\partial \Delta_{k}}{\partial \delta}>0
$$

because equations $(18)^{\sim}(23)$ imply that

$$
\frac{\partial q_{k}}{\partial \delta}>0 \text { and } \frac{\partial \varepsilon_{k}}{\partial \delta}<0
$$

Hence,

$$
\frac{\partial g}{\partial \delta}=\sum_{k=-1}^{0} \frac{\partial g}{\partial \widetilde{q}_{k}} \frac{\partial \widetilde{q}_{k}}{\partial \delta}>0
$$




\section{References}

[1] Aghion, Philippe, Christopher Harris, and John Vickers (1997): "Competition and Growth with Step-by-Step Innovation: An Example", European Economic Review, Papers and Proceedings, vol. 41, 771-782.

[2] Aghion, Philippe, Christopher Harris, Peter Howitt and John Vickers (2001): "Competition, Imitation and Growth with Step-by-Step Innovation", Review of Economic Studies, vol. 68, $467-92$.

[3] Aghion, Philippe, Nicholas Bloom, Richard Blundell, Rachel Griffith and Peter Howitt (2002): "Competition and Innovation: An Inverted U Relationship", NBER Working Paper No. 9269.

[4] Bassanini, Andrea and Ekkehard Ernst (2001): "Labor Market Regulation, Industrial Relations and Technological Regimes: a Tale of Comparative Advantage", Industrial and Corporate Change, vol. 11, 391-426.

[5] Bassanini, Andrea and Ekkehard Ernst (2002): "Labor Market Institutions, Product Market Regulation, and Innovation: Cross-Country Evidence", OECD Economics Department Working Papers No. 316.

[6] Casper, Steven and Henrik Glimstedt (2001): "Economic Organization, Innovation Systems, and the Internet", Oxford Review of Economic Policy, vol. 17, 265-81.

[7] Cecchini-Report (1996): "The Impact and Effectiveness of the Single Market", http://www.europa.eu.int/comm/internal_market/en/update/impact/singleen.pdf, Brussels.

[8] Estevez-Abe, Margarita, Torben Iversen and David Soskice (2001): "Social Protection and the Formation of Skills: A Reinterpretation of the Welfare State", in: Varieties of Capitalism: The Institutional Foundations of Comparative Advantage, Hall, Peter A. and David Soskice (eds.), Oxford University Press, Oxford. 
[9] Fella, Giulio (2000): "Investment in General Training with Consensual Layoffs", Queen Mary, University of London, mimeo.

[10] Levine, David I. (1991): "Just Cause Employment Policies in the Presence of Worker Adverse Selection", Journal of Labor Economics, vol. 9, 294-305.

[11] Levine, David I. and Laura D'A.Tyson (1990): "Participation, Productivity, and the Firm's Environment", in: Paying for Productivity, Alan Blinder (ed.), The Brookings Institution, Washington, D.C.

[12] Nickell, Stephen (1999): "Product Markets and Labor Markets", Labour Economics, vol. 6, $1-20$.

[13] OECD (1999): "Employment Protection and Labor Market Performance", in: OECD Employment Outlook, ch. 2, Paris.

[14] OECD (2001): "The Cross-Market Effects of Product and Labour Market Policies", in: Economic Outlook, vol. 2001/2002, No. 70, ch. 6, Paris.

[15] Saint-Paul, Gilles (1996): Dual Labor Markets: A Macroeconomic Perspective, MIT Press, Cambridge.

[16] Saint-Paul, Gilles (2002): "Employment Protection, International Specialization, and Innovation", European Economic Review, vol. 46, 375-95. 


\section{IZA Discussion Papers}

\begin{tabular}{|c|c|c|c|c|}
\hline No. & Author(s) & Title & Area & Date \\
\hline 874 & J.-S. Pischke & $\begin{array}{l}\text { The Impact of Length of the School Year on } \\
\text { Student Performance and Earnings: Evidence } \\
\text { from the German Short School Years }\end{array}$ & 6 & $09 / 03$ \\
\hline 875 & C. Grund & $\begin{array}{l}\text { Severance Payments for Dismissed Employees } \\
\text { in Germany }\end{array}$ & 3 & $09 / 03$ \\
\hline 876 & $\begin{array}{l}\text { M. Karanassou } \\
\text { H. Sala } \\
\text { D. J. Snower }\end{array}$ & $\begin{array}{l}\text { The European Phillips Curve: Does the NAIRU } \\
\text { Exist? }\end{array}$ & 3 & $09 / 03$ \\
\hline 877 & M.-S. Yun & Decomposing Differences in the First Moment & 3 & $09 / 03$ \\
\hline 878 & $\begin{array}{l}\text { J. T. Addison } \\
\text { C. Schnabel } \\
\text { J. Wagner }\end{array}$ & $\begin{array}{l}\text { The Course of Research into the Economic } \\
\text { Consequences of German Works Councils }\end{array}$ & 3 & $09 / 03$ \\
\hline 879 & $\begin{array}{l}\text { A. Constant } \\
\text { Y. Shachmurove }\end{array}$ & $\begin{array}{l}\text { Entrepreneurial Ventures and Wage Differentials } \\
\text { Between Germans and Immigrants }\end{array}$ & 1 & $09 / 03$ \\
\hline 880 & $\begin{array}{l}\text { W. Koeniger } \\
\text { A. Vindigni }\end{array}$ & $\begin{array}{l}\text { Employment Protection and Product Market } \\
\text { Regulation }\end{array}$ & 2 & $10 / 03$ \\
\hline 881 & R. A. Hart & $\begin{array}{l}\text { Worker-Job Matches, Job Mobility, and Real } \\
\text { Wage Cyclicality }\end{array}$ & 1 & $10 / 03$ \\
\hline 882 & $\begin{array}{l}\text { A. Lindbeck } \\
\text { D. J. Snower }\end{array}$ & The Firm as a Pool of Factor Complementarities & 5 & $10 / 03$ \\
\hline 883 & $\begin{array}{l}\text { S. Groeneveld } \\
\text { J. Hartog }\end{array}$ & $\begin{array}{l}\text { Overeducation, Wages and Promotions within } \\
\text { the Firm }\end{array}$ & 5 & $10 / 03$ \\
\hline 884 & $\begin{array}{l}\text { J. Masso } \\
\text { A. Heshmati }\end{array}$ & $\begin{array}{l}\text { The Optimality and Overuse of Labour in } \\
\text { Estonian Manufacturing Enterprises }\end{array}$ & 4 & $10 / 03$ \\
\hline 885 & $\begin{array}{l}\text { A. Constant } \\
\text { K. F. Zimmermann }\end{array}$ & $\begin{array}{l}\text { The Dynamics of Repeat Migration: A Markov } \\
\text { Chain Analysis }\end{array}$ & 1 & $10 / 03$ \\
\hline 886 & $\begin{array}{l}\text { J. J. Dolado } \\
\text { M. Jansen } \\
\text { J. F. Jimeno }\end{array}$ & $\begin{array}{l}\text { On-the-Job Search in a Matching Model with } \\
\text { Heterogenous Jobs and Workers }\end{array}$ & 1 & $10 / 03$ \\
\hline 887 & $\begin{array}{l}\text { B. Irlenbusch } \\
\text { D. Sliwka }\end{array}$ & $\begin{array}{l}\text { Transparency and Reciprocal Behavior in } \\
\text { Employment Relations }\end{array}$ & 7 & $10 / 03$ \\
\hline 888 & W. Koeniger & $\begin{array}{l}\text { Collective Dismissal Cost, Product Market } \\
\text { Competition and Innovation }\end{array}$ & 3 & $10 / 03$ \\
\hline
\end{tabular}

An updated list of IZA Discussion Papers is available on the center's homepage www.iza.org. 